\title{
BMJ Effects of the Great East Japan Earthquake OPen and huge tsunami on glycaemic control and blood pressure in patients with diabetes mellitus
}

\author{
Susumu Ogawa, ${ }^{1,2}$ Mikihito Ishiki, ${ }^{3}$ Kazuhiro Nako, ${ }^{1}$ Masashi Okamura,,${ }^{1,4}$ \\ Miho Senda, ${ }^{1}$ Takuya Sakamoto, ${ }^{1}$ Sadayoshi Ito ${ }^{1}$
}

To cite: Ogawa $\mathrm{S}$, Ishiki $\mathrm{M}$, Nako K, et al. Effects of the Great East Japan Earthquake and huge tsunami on glycaemic control and blood pressure in patients with diabetes mellitus. BMJ Open 2012;2:e000830.

doi:10.1136/

bmjopen-2012-000830

- Prepublication history and additional figures for this paper is available online. To view these files please visit the journal online (http://dx.doi.org/10.1136/ bmjopen-2012-000830)

Received 10 January 2012 Accepted 15 March 2012

This final article is available for use under the terms of the Creative Commons Attribution Non-Commercial 2.0 Licence; see http://bmjopen.bmj.com

${ }^{1}$ Division of Nephrology, Endocrinology and Vascular Medicine, Tohoku University Hospital, Sendai, Japan ${ }^{2}$ Center for the Advancement of Higher Education, Tohoku University, Sendai, Japan ${ }^{3}$ Iwate Prefectural Takata Hospital, Rikuzentakata, Japan

${ }^{4}$ Center for Translational and Advanced Research, Tohoku University Graduate School of Medicine, Sendai, Japan

Correspondence to Dr Susumu Ogawa; ogawa-s@hosp.tohoku.ac.jp

\section{ABSTRACT}

Objective: To examine the effects of a huge tsunami resulting from the Great East Japan Earthquake on blood pressure (BP) control and glycaemic control in diabetic patients.

Design: A retrospective study.

Setting: Tohoku University, Japan.

Participants: 63 patients were visiting Rikuzentakata Hospital for diabetic treatment before the earthquake and returned to the clinic in July after the earthquake, and they were analysed in the present study. The subjects were divided into two groups: those who were hit by the tsunami, the Tsunami $(+)$ group $(n=28)$, and those who were not, the Tsunami $(-)$ group $(n=35)$, and the groups' parameters and their changes were compared.

Primary outcome measure: Changes of HbA1c. Secondary outcome measures: Changes of $\mathrm{BP}$, body mass index.

Results: $\mathrm{HbA1c}$ and both BP increased, while the numbers of most drugs taken decreased in both groups. Parameter changes were significantly greater in the Tsunami (+) group. All medical data stored at the hospital was lost in the tsunami. The Tsunami (+) patients also had their own records of treatment washed away, so it was difficult to replicate their pre-earthquake drug prescriptions afterwards. In comparison, the Tsunami (-) patients kept their treatment information, making it possible to resume the treatment they had been receiving before the earthquake. The BP rose only slightly in men, whereas it rose sharply in women, even though they had not been directly affected by the tsunami. BP rose markedly in both genders affected by the tsunami.

Conclusions: All medical information was lost in the tsunami, and glycaemic and BP controls of the tsunami-affected patients worsened more than those of patients who had been affected by the earthquake alone. Women may be more sensitive to changes in the living environment that result from a major earthquake than are men.

\section{ARTICLE SUMMARY}

Article focus

- The influences that the large earthquake and the tsunami of March 2011 in Japan exert on blood glucose and BP control are uncertain. Especially, the changes in the blood glucose and the BP after the hospital and patient's home were collapsed by the huge tsunami have not been reported in the past. Furthermore, whether the influences differ according to gender is also uncertain.

Key messages

- Huge tsunamis worsen blood glucose and BP controls more than earthquake damage alone. The reason is that their treatments were not recovered as before the earthquake because patient's medical information had lost completely. The maintenance of the medical information not lost in the earthquake and tsunami is important. The clinical records in the hospital and medicine information at home were swept away by the huge tsunami. Although the change in blood glucose was strongly influenced by tsunamis damage, the change in BP was influenced rather by the gender.

Strengths and limitations of this study

- We first clarified the influence that the large earthquake and the tsunami exerted on the blood glucose and the BP controls. The size of our study was so small that it was difficult for us to analyse it. However, for the future, we do hope for such an analysis to be done on more largescale number of subjects.

\section{INTRODUCTION}

Rikuzentakata is a city located in the southeast of Iwate Prefecture in the Tohoku district of Japan (supplementary figure S1). It has a population of 24000 , with about $34 \%$ aged 65 years or older. The city consists of a small tract of lowland plains along a low shoreline, encircled by highlands (supplementary figure S1). Iwate Prefectural Rikuzentakata Hospital plays a central role in the medical service of 
the region. We have been visiting this hospital twice a month for the past 2 decades to treat diabetic outpatients. Although most patients had poor glycaemic control and advanced organ disorders when we took over their treatment, long-term treatment resulted in well-controlled blood glucose (BG) and blood pressure (BP) levels in a large number of the patients.

On 11 March 2011, at 14:46, a huge magnitude 9.0 earthquake struck this area, its epicentre ca. $130 \mathrm{~km}$ to the east, off Oshika Peninsula in Miyagi Prefecture. About 20 min later, a massive tsunami more than $10 \mathrm{~m}$ high hit the city ${ }^{1}$ (supplementary figure S2). Approximately 2000 people died or disappeared. The town was demolished, and the hospital completely destroyed (supplementary figure S3). About 30000 medical charts were washed away, and patient information stored on computer systems completely disappeared (supplementary figure S4). Numerous medical personnel rushed to the area from all over Japan to help treat survivors, and many lives were saved as a result.

In July 2011, about 4 months later, we finally resumed outpatient practice at a makeshift clinic (supplementary figure S5). The glycaemic and BP controls of patients who had survived the ordeal had worsened due to traumatic changes in their living environments. There was, however, a marked difference in the level of deterioration of glycaemic and BP controls between those who had lived in the plains area, which had been struck by the tsunami, and those who had lived on higher ground and who had thus escaped its full effects. We felt that identifying the reasons for this difference would be useful in establishing a medical setup that could, in future, prevent deterioration of glycaemic and BP controls during times of disaster.

It appears that disasters of this scale can happen anywhere in the world. History demonstrates that such major earthquakes and tsunamis have occurred repeatedly. ${ }^{2}$ We therefore feel that analysing our experiences on this occasion and reporting them is important for establishing a medical setup that can withstand such major disasters. This is what prompted us to publish this report.

\section{METHODS}

Before the earthquake, approximately 120 patients were visiting Rikuzentakata Hospital for diabetic treatment. Only 63 patients returned to the clinic in July after the earthquake, and it is they who were analysed in the present study. They were divided into two groups: the Tsunami (+) group, whose members lived in the lowland areas and who were hit by the tsunami $(n=28)$, and the Tsunami (-) group, whose members lived on higher ground and who were not hit by the tsunami $(n=35)$.

Body mass index (BMI), BG levels (not necessarily fasting), haemoglobin A1c (HbA1c (JDS)), systolic blood pressure (SBP) and diastolic blood pressure (DBP) were established as items for analysis and were measured 4 months after the earthquake. All patients' medical data before the earthquake, which had been stored at the hospital, had been lost. However, we had collected and stored all patients' data in October 2010 for another study, ${ }^{3}$ which was used as the pre-earthquake data on this occasion. The values for each parameter were compared thus: for the whole study group, each parameter after the earthquake was compared with its value before the earthquake. Similarly, parameters of the Tsunami (-) group before the earthquake were compared with those of the Tsunami (+) group before the earthquake, and parameters of the Tsunami (-) group after the earthquake were compared with those of the Tsunami $(+)$ group after the earthquake. Changes also occurred in patients' use of drugs following the disaster. Such changes were analysed in two categories of drugs, hypoglycaemic and antihypertensive agents, by comparing the number of patients administered each drug. In addition, the absolute changes and percentage changes in their glycaemic and $\mathrm{BP}$ controls, and those in their drug therapies, were analysed. We are receiving informed consent from the patients and the family for this research.

\section{STATISTICAL ANALYSIS}

Normally distributed values are presented as mean \pm SEM. The obtained values of the parameters and of drug use were compared within the whole study group (before vs after) and between the Tsunami $(-)$ and the Tsunami $(+)$ groups, using Student $t$ test. The change from before the earthquake to after was calculated for each parameter. The change undergone by the Tsunami $(-)$ group was compared with that undergone by the Tsunami (+) group by means of analysis of variance. Similarly, changes affecting male patients were compared with those affecting female patients, using the Mann-Whitney U test. The $\chi^{2}$ test was used to compare percentage changes in parameters and use of drugs between the Tsunami (-) and the Tsunami (+) groups, and a similar analysis of BP was performed, comparing men with women. Multiple regression analysis was used to identify whether tsunami exposure was an independent risk factor for the percentage increase of HbAlc, SBP and DBP after the disaster. $\mathrm{p}<0.05$ was regarded as statistically significant.

\section{RESULTS}

Table 1 shows means with SEs of each parameter for all subjects before and after the earthquake. Only BMI decreased; BG, HbA1c, SBP and DBP rose significantly.

There were also some changes in the use of drugs (represented by the number of patients administered the drug) after the disaster (table 2). The use of most antihyperglycaemics decreased by $30 \%-40 \%$, except $\alpha$ glucosidase inhibitors (AGIs) and glucagon-like polypeptide (GLP)-1 analogues. GLP-1 analogues were employed with only two patients - too small a number to analyse statistically. The number administered AGIs did not change after the earthquake. With antihypertensives, use of renin-angiotensin system inhibitors (RASIs) 
Table 1 Parameters (BMI, glycaemic control and blood pressure control) of all study subjects before and after the earthquake

\begin{tabular}{llll}
\hline $\mathrm{n}$ & 63 & & \\
Age (years) & $68.1 \pm 1.4$ & & \\
M/F & $29 / 34$ & & $\mathrm{p}$ Value \\
& Before & After & $<0.01$ \\
$\mathrm{BMI}\left(\mathrm{kg} / \mathrm{m}^{2}\right)$ & $25.8 \pm 0.5$ & $25.5 \pm 0.5$ & $<0.01$ \\
$\mathrm{BG}(\mathrm{mg} / \mathrm{dl})$ & $109.4 \pm 3.9$ & $134.3 \pm 7.2$ & $<0.01$ \\
$\mathrm{HbA1c}(\mathrm{JDS})(\%)$ & $5.9 \pm 0.2$ & $6.5 \pm 0.2$ & $<0.01$ \\
SBP $(\mathrm{mm} \mathrm{Hg})$ & $121.0 \pm 1.2$ & $136.1 \pm 2.9$ & $<0.01$ \\
DBP $(\mathrm{mm} \mathrm{Hg})$ & $67.2 \pm 1.0$ & $74.1 \pm 1.6$ & $<0.01$ \\
\hline
\end{tabular}

Data are represented as mean \pm SEM.

$\mathrm{BG}$, blood glucose concentration; BMI, body mass index; DBP, diastolic blood pressure; F, female; HbA1c (JDS), glycosylated haemoglobin A1c; M, male; SBP, systolic blood pressure.

reduced most drastically, followed by other antihypertensives ( $\beta$ blockers, $\alpha$ blockers, etc), diuretics and calcium channel blockers, in order of decreasing reduction in use.

Within each group, changes in parameters were analysed (table 3). In both groups, BMI decreased, while BG, HbAlc, SBP and DBP significantly increased following the earthquake. The values of each parameter before and after the earthquake were compared between the Tsunami (-) and the Tsunami (+) groups. Although no differences were observed in the groups' pre-earthquake values, values of BG, HbA1c, SBP and DBP afterwards were significantly higher in the Tsunami $(+)$ group than in the Tsunami $(-)$ group $(\mathrm{p} 4<0.05)$. No differences in BMI were observed between the groups, even after the earthquake.

Changes and percentage changes in BG, HbAlc, SBP and DBP were compared between the Tsunami $(-)$ and the Tsunami (+) groups (supplementary figure S6). All

Table 2 The use of diabetic treatment drugs and antihypertensive drugs before and after the earthquake and their percentage changes

\begin{tabular}{lccc}
\hline & Before & After & \% Change \\
\hline Hypoglycaemic agents & & & \\
$\quad$ Sulfonylureas & 26 & 16 & -38.5 \\
Glinides & 27 & 18 & -33.3 \\
$\alpha$-Glucosidase inhibitors & 29 & 29 & 0 \\
Biguanides & 44 & 28 & -36.4 \\
Pioglitazone & 28 & 18 & -35.7 \\
DPP-4 inhibitors & 22 & 15 & -31.8 \\
Insulin therapies & 26 & 17 & -34.6 \\
GLP-1 analogues & 2 & 0 & -100.0 \\
Antihypertensive agents & & & \\
RAS inhibitors & 36 & 7 & -80.6 \\
CCBs & 32 & 22 & -31.3 \\
Diuretics & 23 & 7 & -69.6 \\
Others & 15 & 3 & -80.0 \\
\hline CCB, calcium channel blocker; DPP-4, dipeptidyl peptidase-4; \\
GLP-1, glucagon-like polypeptide-1; RAS, renin-angiotensin \\
system.
\end{tabular}

percentage changes in these parameters were significantly higher in the Tsunami (+) group, so though all patients were affected by the same disaster, glycaemic and BP controls deteriorated more in patients with tsunami exposure.

An overview of changes in usage of various drug treatments in both the Tsunami $(-)$ and the Tsunami (+) groups is given in table 4, which represents the number of patients taking each drug. Use of most drugs decreased in both groups following the earthquake. Administration of all anti-hyperglycaemic drugs except AGIs decreased more in the Tsunami (+) group than in the Tsunami (-) group. The decrease in the number of patients undergoing AGI treatment was $0 \%$ for both groups. After the earthquake, the use of dipeptidyl peptidase (DPP)-4 inhibitors and GLP-1 analogue halted completely and that of insulin decreased greatly in the Tsunami (+) group, yet their use did not decrease much or at all in the Tsunami $(-)$ group. The use of all antihypertensive drugs decreased in both groups. In particular, the use of RASIs, other antihypertensives (eg, sympatholytic agents) and diuretics decreased more in the Tsunami (+) group than in the Tsunami $(-)$ group. Additionally, the percentage decrease in the use of RASIs, diuretics and others was significantly larger than of calcium channel blockers for both groups $\left(p<0.05, \chi^{2}\right.$ test, results not shown).

Multiple regression analysis was performed using age, gender and tsunami exposure, as well as percentage changes in BMI, BG and HbAlc as independent variables and percentage changes in $\mathrm{HbAlc}$, SBP and DBP as dependent variables (table 5). Our results show that tsunami exposure was an independent risk factor for increases in HbAlc. It was not an independent risk factor for BP changes, while gender was: women demonstrated greater increases in BP after the earthquake than men (supplementary figure S7), while tsunami exposure caused no difference in levels of BP elevation (table 5). So, women experienced BP rises even without tsunami exposure (supplementary figure S8, p3 $=\mathrm{NS}$ ), and by contrast, though BP rose sharply in male members of the Tsunami (+) group, the rise was minimal among those of the Tsunami (-) group (supplementary figure $\mathrm{S} 8, \mathrm{p} 4<0.05)$.

The drug compliance after the earthquake was not defective regardless of existence of the tsunami damage or the gender. The drug compliance in the female members of the Tsunami (-) group was not especially poor.

\section{DISCUSSION}

It has been reported that a major disaster significantly exacerbated the controls of both glycaemic and BP. These controls have deteriorated similarly in our research. The patients' living environment drastically changed after the earthquake and tsunami. Most lived in evacuation centres during the first month after the incident, which perhaps prevented them from receiving 
Table 3 The comparison of each parameter in the Tsunami (-) and Tsunami (+) groups

\begin{tabular}{|c|c|c|c|c|c|c|c|c|}
\hline & \multicolumn{3}{|c|}{ Tsunami (-) } & \multicolumn{5}{|c|}{ Tsunami (+) } \\
\hline & Before & After & p1 & Before & After & p2 & p3 & p4 \\
\hline$n$ & \multicolumn{3}{|l|}{35} & \multicolumn{5}{|l|}{28} \\
\hline Age (years) & \multicolumn{3}{|l|}{$67.8 \pm 2.0$} & \multicolumn{2}{|l|}{$68.4 \pm 2.1$} & \multicolumn{3}{|l|}{ NS } \\
\hline $\mathrm{M} / \mathrm{F}$ & \multicolumn{3}{|l|}{$18 / 17$} & \multicolumn{5}{|l|}{$11 / 17$} \\
\hline BMI $\left(\mathrm{kg} / \mathrm{m}^{2}\right)$ & $26.0 \pm 0.7$ & $25.7 \pm 4.3$ & $<0.05$ & $25.6 \pm 0.8$ & $25.1 \pm 0.8$ & $<0.05$ & NS & NS \\
\hline$B G(m g / d l)$ & $112.0 \pm 5.0$ & $121.7 \pm 7.1$ & $<0.05$ & $106.3 \pm 6.1$ & $150.8 \pm 13.0$ & $<0.01$ & NS & $<0.05$ \\
\hline $\mathrm{HbA1c}(\%)$ & $5.9 \pm 0.1$ & $6.1 \pm 0.1$ & $<0.05$ & $5.9 \pm 0.1$ & $7.0 \pm 0.3$ & $<0.01$ & NS & $<0.01$ \\
\hline $\mathrm{SBP}(\mathrm{mm} \mathrm{Hg})$ & $122.1 \pm 1.8$ & $133.8 \pm 4.2$ & $<0.05$ & $119.6 \pm 1.3$ & $139.0 \pm 3.7$ & $<0.01$ & NS & $<0.01$ \\
\hline DBP (mm Hg) & $68.1 \pm 1.6$ & $73.8 \pm 2.1$ & $<0.01$ & $66.1 \pm 1.1$ & $74.6 \pm 2.2$ & $<0.01$ & NS & $<0.05$ \\
\hline \multicolumn{9}{|c|}{$\begin{array}{l}\text { Data are represented as means } \pm \text { SEM. } \\
\text { p1, before versus after in the Tsunami }(-) \text { group. } \\
\text { p2: before versus after in the Tsunami }(+) \text { group. } \\
\text { p3, Tsunami }(-) \text { group versus Tsunami }(+) \text { group before the earthquake. } \\
\text { p4, Tsunami }(-) \text { group versus Tsunami }(+) \text { group after the earthquake. } \\
\text { BMI, body mass index; BG, blood glucose concentration; DBP, diastolic blood pressure; F, female; HbA1c (JDS), glycosylated haemoglobin } \\
\text { A1c; M, male; SBP, systolic blood pressure. }\end{array}$} \\
\hline
\end{tabular}

sufficient supplies of food and drugs. From the second month on, the Tsunami (+) group was moved to makeshift housing units, while the Tsunami (-) group returned home. There were still food shortages, with rationing of certain items. Fresh foods like vegetables and fish were in particularly short supply, so patients mostly subsisted on preserved foods like sweets, pastries, canned products, cup noodles and boil-in-the-bag foods. It is reasonably speculated that inappropriate diet in refuge life may have affected BP control through an increase of salt intake by some of supplied food such as instant noodles. Two months after the earthquake, supplies of drugs returned to about pre-earthquake levels, but the food situation had still not completely recovered. Utility services-power, water and gas-had not completely recovered even after 3 months, although they steadily approached pre-earthquake levels. Under these conditions, it was difficult to ensure that patients stuck to diet and exercise therapies. We believe that this was one reason for the deterioration in glycaemic and BP controls. A significant temporary exacerbation in the glycaemic control was found after the Great HanshinAwaji Earthquake. An inappropriate diet demonstrated the highest risk factor to exacerbate the glycaemic control. $^{5}$ It has been reported that SBP increased significantly within 3 months after a major earthquake struck the Niigata Prefecture, Japan, 2004, and returned to pre-earthquake level at 6 months. ${ }^{6}$ We evaluated BP at 4 months after the earthquake.

Even under circumstances where loss of body weight appeared inevitable and where in fact many patients did lose weight, there was some who managed to gain weight. Weight loss was probably caused by insufficient food intake in some patients and by deteriorated glycaemic control in others. Meanwhile, ingestion of preserved foods rich in sugar and fats may, for some other patients, have led to excessive intake of such nutrients, resulting in weight gain. Some patients

Table 4 Changes in the use of various drug treatment in the Tsunami (-) and Tsunami (+) groups

\begin{tabular}{|c|c|c|c|c|c|c|c|}
\hline & \multicolumn{3}{|c|}{ Tsunami (-) } & \multicolumn{3}{|c|}{ Tsunami (+) } & \multirow[b]{2}{*}{ p Value } \\
\hline & Before & After & $\%$ Change 1 & Before & After & $\%$ Change 2 & \\
\hline \multicolumn{8}{|l|}{ Hypoglycaemic agents } \\
\hline Sulfonylureas & 15 & 11 & -26.7 & 11 & 5 & -54.6 & $<0.01$ \\
\hline Glinides & 18 & 16 & -11.1 & 9 & 2 & -77.8 & $<0.01$ \\
\hline$\alpha$-Glucosidase inhibitors & 17 & 17 & 0 & 12 & 12 & 0 & NS \\
\hline Biguanides & 27 & 25 & -7.4 & 17 & 3 & -82.4 & $<0.01$ \\
\hline Pioglitazone & 19 & 17 & -10.5 & 9 & 1 & -88.9 & $<0.01$ \\
\hline DPP-4 inhibitors & 16 & 15 & -6.3 & 6 & 0 & -100.0 & $<0.01$ \\
\hline Insulin therapies & 13 & 13 & 0.0 & 13 & 4 & -69.2 & $<0.01$ \\
\hline GLP-1 analogues & 0 & 0 & 0.0 & 2 & 0 & -100.0 & - \\
\hline \multicolumn{8}{|l|}{ Antihypertensive agents } \\
\hline RAS inhibitors & 20 & 7 & -65.0 & 7 & 0 & -100.0 & $<0.01$ \\
\hline CCBs & 17 & 15 & -11.8 & 15 & 7 & -53.3 & $<0.01$ \\
\hline Diuretics & 13 & 6 & -53.9 & 10 & 1 & -90.0 & $<0.01$ \\
\hline Others & 7 & 3 & -57.1 & 8 & 0 & -100.0 & $<0.01$ \\
\hline
\end{tabular}


Table 5 Results of multiple regression analyses, using the percentage changes in HbA1c, SBP and DBP as dependent variables and some parameters as independent variables

\begin{tabular}{|c|c|c|c|c|c|c|}
\hline \multirow[b]{3}{*}{ Independent variables } & \multicolumn{6}{|c|}{ Dependent variables } \\
\hline & \multicolumn{2}{|c|}{$\%$ Change of HbA1c } & \multicolumn{2}{|c|}{$\%$ Change of SBP } & \multicolumn{2}{|c|}{$\%$ Change of DBP } \\
\hline & $\beta$ & $\mathbf{p}$ & $\beta$ & $\mathbf{p}$ & $\beta$ & p \\
\hline Age & -0.08 & 0.60 & 0.05 & 0.79 & -0.07 & 0.69 \\
\hline Gender & 0.84 & 0.81 & -6.94 & 0.08 & -9.21 & 0.03 \\
\hline$\%$ Change in BMI & 0.22 & 0.75 & 0.60 & 0.44 & 0.49 & 0.56 \\
\hline$\%$ Change in $B G$ & 0.04 & 0.18 & 0.04 & 0.25 & 0.05 & 0.12 \\
\hline$\%$ Change in $\mathrm{HbA} 1 \mathrm{c}$ & - & - & 0.15 & 0.31 & 0.23 & 0.15 \\
\hline Exposure to tsunami & 11.37 & 0.00 & 2.55 & 0.57 & -2.29 & 0.64 \\
\hline
\end{tabular}

developed hypoglycaemia, as food was distributed through rationing, and they could no longer supplement a lack of calories by eating items like snack food between meals.

The chief reason for the worsening of glycaemic and BP controls after the incident was probably the changes in the drugs administered. Had this survey been carried out immediately after the earthquake, such changes might have been attributable to insufficient supply of some types of drugs. However, when we conducted this survey, 4 months after the incident, drugs were already available in sufficient quantities. Despite this, fewer drugs were being administered to patients than they had received before the earthquake, impairing their patients' glycaemic and BP controls. One possible reason for this is that, in conjunction with the changes in the living environment, patients might have been examined by and prescribed different less effective drugs by a physician other than their attending doctor. Under conditions where meals are supplied at random intervals, drugs that are liable to cause hypoglycaemia, like sulfonylurea derivatives, glinides and insulin, are difficult to use.

In times of water shortage, drugs that carry risks of dehydration and acute renal failure (like RASIs and diuretics) or of heart failure (like pioglitazone) are contraindicated if a patient's physical status, including renal and cardiac function, is unknown. Sympathetic blockers are also difficult to use under such conditions. Additionally, in older patients with unclear renal function, such difficulty in prescribing applies to biguanides as well. The only biguanide derivative used at Rikuzentakata Hospital before the earthquake was buformin. Since its use is contraindicated in older patients and in those with reduced kidney function, eight patients switched to metformin, which should be administered 'with caution'. Because of this, prescriptions of biguanides decreased after the disaster, and the number of patients who used metformin increased. Moreover, DPP4 inhibitors and GLP-1 analogue therapy were not used, probably because they had been released only recently in Japan, and their modes of use had not yet become fully known to non-specialists. It thus appeared that because of these circumstances, physicians frequently used AGIs, which are less liable to induce hypoglycaemia and which cause minimal adverse events. Furthermore, during the first 3 months after the disaster, the medical setup was such that, instead of a single physician providing continuous treatment, various physicians from all over Japan (not necessarily diabetes or hypertension specialists) took turns examining patients, making it even more difficult to administer medications satisfactorily.

Though these conditions were the same for both groups, the level of deterioration in glycaemic and BP controls differed markedly between the Tsunami $(+)$ and the Tsunami (-) groups, most likely because the administration of drugs in the Tsunami (+) group had substantially decreased. The reasons for this may be as follows: it has been reported that the higher the magnitudes scales of earthquakes were, the higher the mental stress and the psychological damage were. ${ }^{7}$ There is an association between life-threatening stress in a natural disaster and the worsening of metabolic and BP controls in patients with diabetes mellitus. We speculate that these stresses in the Tsunami (+) group were far larger than those in the Tsunami (-) group. ${ }^{8}$ Even after the earthquake, the Tsunami (-) group patients had records of their treatment status on hand, like their diabetes databook for clinical co-operation and their medicine notebook, which lists drugs they are using. Moreover, immediately after the earthquake, they had leftover drugs prescribed immediately before (a day or 15 days before) the incident. So patients in the Tsunami (-) group were able to immediately resume their preearthquake treatment. ${ }^{10}$ In contrast, all such treatment information for patients in the Tsunami (+) group had been swept away by the tsunami. In addition, patient information previously stored in the hospital was also lost, making it impossible to resume the exact treatment they had been receiving before the disaster. Therefore, patients in the Tsunami (+) group found themselves starting a completely new treatment regimen after the disaster. This appears to have drastically worsened their glycaemic and BP controls. Despite belonging to the Tsunami (+) group, two patients had their medicine 
notebook with them, allowing them to immediately resume their pre-disaster treatment without causing aggravation of their glycaemic or BP control.

No such phenomena were observed in nearby hospitals standing on higher ground, which did not suffer any tsunami damage. Needless to say, it is important to build hospitals that are not prone to tsunami damage. Even more crucial is to have patients' medical information-especially the details of treatments-stored not only by patients and hospitals but also at a different, possibly central, location. We believe that such centralised management is necessary and may prevent patients' disease status from aggravating after a major disaster.

In men, BP rose strikingly only in the Tsunami (+) group. This appears to have been caused by the sharp decrease in the administration of antihypertensive drugs. In female patients, however, BP rose similarly in the Tsunami (-) and Tsunami (+) groups. This may imply that, while men are not very likely to develop BP rise as a result of an earthquake alone, women are likely to develop BP elevation as a result of only an earthquake and that life after earthquakes may be more stress inducing for women than for men (perhaps because of the challenges of ensuring a hygienic environment, toilets, bathing, supplies of female sanitary products and problems with resuming work). ${ }^{8} 911$ The Hanshin-Awaji earthquake resulted in an increase of cardiovascular events such as myocardial infarctions and stroke, particularly in women, with the increase occurring in two or three times frequency of men. ${ }^{12}$ Earthquakes provide a strong acute and chronic stress; the stress might be strong in a woman especially. The stronger stress can trigger cardiovascular events predominantly through sympathetic nervous activation and potentiation of acute risk factors such as BP increase. It may be that women need more meticulous care than men after a major earthquake disaster, such as the present incident.

Tsunamis worsen patients' glycaemic and BP controls for a long period after they strike, and this period may extend to several months. Clearly, storing and managing patients' treatment information is extremely important. However, even when treatment information was not destroyed or lost, some patients' symptoms worsened because they had lost wives who had helped them with their diet therapy or because the daughter who had cared for them had died. Needless to say, protecting people's lives, including family members', is the most important goal, and we need to focus on establishing disaster prevention setups that place the utmost priority on saving lives. We feel that hospitals, which become key bases for providing medical services in areas during times of disaster, should be built in disaster-proof locations (high ground in the case of this earthquake).

Acknowledgements We wish to express our heartfelt admiration and gratitude to the nutritionists, pharmacists and nurses in Rikuzentakata
Hospital who, despite being victims themselves, visited every evacuation centre and temporary housing centre to gather detailed and valuable information on the patients' meal status, drug dosing situations and physical status. Our deep thanks also go to the doctors (especially Dr Masaaki Shimanuki and Dr Masahiro Ueno) of Rikuzentakata Hospital, who offered us their valuable materials and photographs. Furthermore, we would like to thank Ms Manami Shimizu and Ms Mai Sasaki for their efforts in editing and sorting out the huge volume of materials and documents and in drawing up figures and tables.

Contributors SO researched data, wrote manuscript and contributed to discussion. MI is a director of Rikuzentakata Hospital. He offered the data and the information necessary for this investigation. MI does not only offer data but also participates in the discussion, in the locale information gathering and in acquisition of the informed consent. KN, MO, MS and TS researched data and contributed discussion. SI contributed to discussion and reviewed/edited the manuscript. All authors made the final approval of the version to be published.

Funding This research did not receive any specific grant from any funding agency in the public, commercial or not-for-profit sector. This work was done within the health insurance treatment.

\section{Competing interests None.}

Patient consent Because there is no photograph that the personal name and the individual can specify in our manuscript.

Ethics approval The study was performed in line with ethical guidelines in accordance with the Declaration of Helsinki. Data are presented in aggregate, and no personal health information is disclosed. Iwate Prefectural Takata Hospital Ethics Committee.

Provenance and peer review Not commissioned; externally peer reviewed.

Data sharing statement Please contact S0, corresponding author, when you want further information of our original research article.

\section{REFERENCES}

1. Shibahara S. The 2011 Tohoku earthquake and devastating tsunami. Tohoku J Exp Med 2011;223:305-7.

2. Minoura K, Imamura F, Sugawara D, et al. The 869 Jogan tsunami deposit and recurrence interval of large-scale tsunami on the Pacific coast of northeast Japan. J Nat Disast Sci 2001;23:83-8.

3. Ogawa S, Ishiki M, Nako K, et al. Sitagliptin, a dipeptidyl peptidase-4 inhibitor, decreases systolic blood pressure in Japanese hypertensive patients with type 2 diabetes. Tohoku J Exp Med 2011;223:133-5.

4. Fonseca VA, Smith $\mathrm{H}$, Kuhadiya $\mathrm{N}$, et al. Impact of a natural disaster on diabetes: exacerbation of disparities and long-term consequences. Diabetes Care 2009;32:1632-8.

5. Kirizuka K, Nishizaki H, Kohriyama K, et al. Influences of The Great Hanshin-Awaji Earthquake on glycemic control in diabetic patients. Diabetes Res Clin Pract 1997;36:193-6.

6. Kamoi K, Tanaka M, Ikarashi T, et al. Effect of the 2004 Mid-Niigata Prefecture earthquake on home blood pressure measurement in the morning in type 2 diabetic patients. Clin Exp Hypertens 2006;28:719-29.

7. Inui $\mathrm{A}$, Kitaoka $\mathrm{H}$, Majima $\mathrm{M}$, et al. Effect of the Kobe earthquake on stress and glycemic control in patients with diabetes mellitus. Arch Intern Med 1998;158:274-8.

8. Kumar MS, Murhekar MV, Hutin Y, et al. Prevalence of posttraumatic stress disorder in a coastal fishing village in Tamil Nadu, India, after the December 2004 tsunami. Am J Public Health 2007;97:99-101.

9. Ramachandran A, Snehalatha C, Yamuna A, et al. Stress and undetected hyperglycemia in southern Indian coastal population affected by tsunami. J Assoc Physicians India 2006;54:109-12.

10. Kamoi K, Tanaka M, Ikarashi T, et al. Effect of the 2004 Mid Niigata Prefecture earthquake on glycemic control in type 1 diabetic patients. Diabetes Res Clin Pract 2006;74:141-7.

11. Prueksaritanond S, Kongsakol R. Biopsychosocial impacts on the elderly from a tsunami-affected community in southern Thailand. $J$ Med Assoc Thai 2007;90:1501-5.

12. Kario K, McEwen BS, Pickering TG. Disasters and the heart: a review of the effects of earthquake-induced stress on cardiovascular disease. Hypertens Res 2003;26:355-67. 